\title{
Electric vehicles and low voltage grid: impact of uncontrolled demand side response
}

Conference or Workshop Item

Accepted Version

Hattam, L., Vukadinovic Greetham, D., Haben, S. and Roberts, D. (2017) Electric vehicles and low voltage grid: impact of uncontrolled demand side response. In: 24th International Conference on Electricity Distribution, 12-15 June 2017, Glasgow, pp. 1073-1076. Available at http://centaur.reading.ac.uk/69917/

It is advisable to refer to the publisher's version if you intend to cite from the work. See Guidance on citing.

Published version at: https://doi.org/10.1049/oap-cired.2017.0651

Publisher statement: This paper was first published at CIRED.

All outputs in CentAUR are protected by Intellectual Property Rights law, including copyright law. Copyright and IPR is retained by the creators or other copyright holders. Terms and conditions for use of this material are defined in 
the End User Agreement.

www.reading.ac.uk/centaur

\section{CentAUR}

Central Archive at the University of Reading

Reading's research outputs online 


\title{
ELECTRIC VEHICLES AND LOW VOLTAGE GRID: IMPACT OF UNCONTROLLED DEMAND SIDE RESPONSE
}

\author{
Laura HATTAM Danica VUKADINOVIC GREETHAM Stephen HABEN \\ University of Reading-UK University of Reading-UK \\ 1.hattam@reading.ac.uk \\ d.v.greetham@reading.ac.uk \\ University of Oxford-UK \\ David ROBERTS \\ Stephen.Haben@maths.ox.ac.uk David.Roberts@eatechnology.com
}

\begin{abstract}
We are looking at the impact of electric vehicles (EV) charging from low voltage (LV) networks. Based on the data obtained from two different pilot projects:

1. Mini-E trial where EV users were incentivised to charge during the night;

2. My Electric Avenue trial where there were no similar incentives,

we want to quantify the impact of EV charging, presuming that the number of home-charging EV users will increase significantly in the near future.

By assuming that the current load at individual household level is known or inferred, simulations are performed to estimate the future load. We look at different percentages of EV uptake and model clustered scenarios, where the social networking effect is imposedusers adopt an EV with a higher probability if their neighbour already has one.

Our simulations demonstrate that incentivising night-time charging can create large new peaks during the night, which could have negative effects on low voltage networks. On the other hand, simulations based on the data with no incentives shows that naturally occurring diversity in charging behaviour does not automatically result in comparable network stress at the same penetrations.
\end{abstract}

\section{INTRODUCTION}

The current trends in per-household domestic demand on low voltage (LV) networks in developed countries (in the UK they have remained relatively stable or decreased in the last 11 years) reveal that the increase in domestic demand will be due mainly to new builds and the uptake of electric vehicles and heat pumps. Given the ratio of EV charging to other parts of the load, static and uncontrolled time of use tariffs could result in new large peaks developing. This situation will worsen on local networks if these new loads are clustered. Several recent studies have explored in detail the impact of EVs on the network $[1,2,3,4,5,6]$. Whilst these investigations do suggest that there are benefits of demand side response, uncontrolled applications of time of use tariffs or direct action mechanisms could be extremely detrimental to low voltage networks, which were designed with behavioural diversity taken into account.

In this paper, we analyse a low voltage network with realistic demand profiles and compare the impact of charging electric vehicles with real data from two trials. In the first trial, EV users were incentivised to charge their vehicles during the night and in the second, there were no incentives. We simulate a clustered uptake of electric vehicles through neighbourhoods. Consequently, social influences on human behaviour are captured, which are sometimes interpreted as imitating or keeping up with your neighbours. Using realistic data for the base-load (daily household electricity load not including EV demand), simulated electric vehicle charging is added. Then, probabilistic techniques are applied to obtain confidence bounds at a feeder level for different electric vehicle charging scenarios.

In the next section, the datasets used for our analysis are described, followed by Methodology and Results. Finally, in the Discussion, we propose the steps that can mitigate unwanted impacts of synchronized EV charging, whilst avoiding over-complicated technical solutions.

\section{DATASETS}

Our LV network is based on a real network in Bracknell, UK and comprises of 98 feeders and 26 substations with 4073 households and 121 commercial properties in total. We model an LV network on a winter, spring and summer day, and on a half-hourly basis (only the results for summer are shown here). Therefore, there are 48 values in $\mathrm{kW}$ for each household, on each day.

\section{Base-load}

Each household is assigned an initial base-load, which varies for the three modelled days. The base-load is obtained from smart metered data of sample households in the real LV network. The sample points are then coupled with non-metered households using a genetic algorithm [7] that optimizes the match between the aggregated coupled loads and the measured substation feeder level loads.

\section{Mini-E trial}

The Mini-E trial was an EV charging trial that ran in 2009 and 2010. The data consists of half-hourly charging profiles of 19 EVs collected by Scottish and Southern Electricity Networks. The users were incentivised to charge overnight, which is evident from the data. Box plots of charging patterns over winter, spring and summer can be found in [5]. 


\section{My Electric Avenue}

The My Electric Avenue data comprises various EV charging profiles that were collected between the $23^{\text {rd }}$ January 2014 and the $11^{\text {th }}$ February 2015 . Although there were $228 \mathrm{EVs}$ in total taking part in this trial, after choosing ones that consistently participated between the weeks 16-52 of the trial in order to collect winter, spring and summer sets, 79 daily profiles per season were obtained. Profiles have readings every half hour and consist of ' 0 ' when they are not charging and ' $3.7 \mathrm{~kW}$ ' when charging. The My Electric Avenue profiles vary over the seasons, weekdays and weekends. Moreover, they can be grouped by charging behaviour into several different clusters of comparable sizes, thus representing diverse charging behaviour. Here, only the results associated with summer are presented. Unlike other typical UK domestic loads, EV charging does not reduce in the summer and therefore coincides with lower network capacity as reduced cable and transformer ratings apply. To examine more extreme scenarios, only the non-zero EV profiles were used from the summer set. This gave 24 profiles that are depicted in Figure 1, where the black squares represent a half hour when $\mathrm{EV}$ is charging.

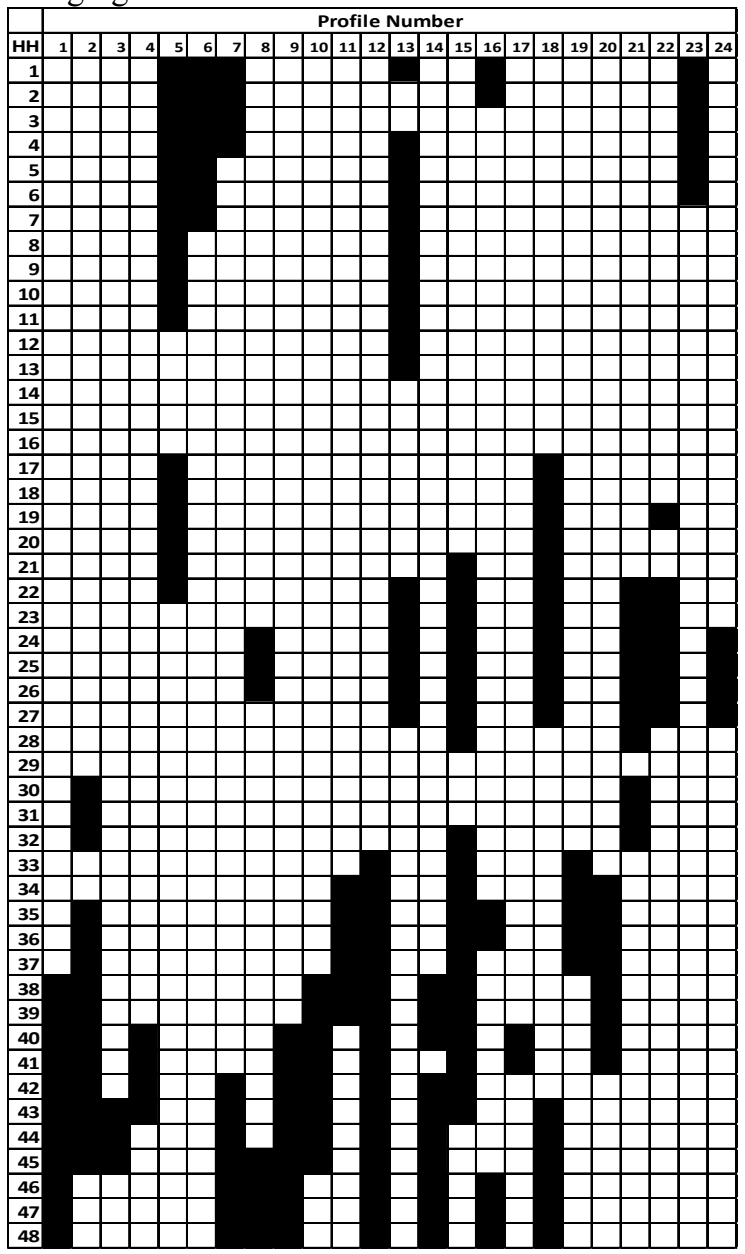

Figure 1: Non-zero EV profiles recorded on Thursday, 10/07/14. The first column has the half hours and the black squares indicate a half hour of EV charging.

\section{METHODOLOGY}

Simulations were undertaken with a time step of one year to assign EVs to households in a clustered manner. The EV datasets from the two trials were applied and then the results compared.

To obtain clusters, in each year of the simulation, we assigned a probability of acquiring an EV to be proportional to the score $\mathrm{s}$, where $s=100\left(\frac{n_{E V}}{n}\right), n_{E V}$ is the number of neighbours - households on the same feeder that already have an $\mathrm{EV}$, and $n$ is the total number of households on that feeder. Households were randomly allocated an EV using s. The number of assigned EVs increased linearly each year until the predetermined final number of EVs was attained.

Initially, a small proportion of EVs were assigned randomly with a probability that corresponded to the household's council tax band. This ensured that the early EV adopters in our model lived mostly in larger properties, with off road parking assumed.

The final percentages of households that were assigned EVs by the simulations were $10 \%, 30 \%$ and $50 \%$ of the total population (4073 households). These models ran over 8 years, as this is a single price control review period set by the UK regulatory authority for gas and electricity markets, OFGEM in 2015. Distribution Network Operators (DNOs) in the UK have to develop detailed investment plans using this time horizon, which informed our choice. The uptake during this time horizon was linear as only the final result was of interest - the geographical spread of EVs after 8 years. As the assumed penetration percentages are given in advance, this model then allowed us to explore confidence bounds obtained from 500 runs using different clustered geographical distributions of EVs. In contrast, prominent clusters of a comparable size do not occur after 500 runs when social influence is not enforced within the model (uniformly at random assignments). For both EV datasets, the assigned EV profiles were chosen from a sample of profiles that correspond to the same season and the same weekday.

See [6] for further detail on the clustering method and the calculation of confidence bounds.

\section{Results using the Mini-E trial dataset}

As the customers were incentivised to charge during the night throughout this trial, night-time peaks were expected with a clustered distribution. The results for $50 \%$ EV uptake are shown in Figures 2 and 3. The 10\%, $50 \%$ and $90 \%$ quantile load are depicted at feeders 67 and 72 , which have 35 and 99 households respectively. These were computed from 500 runs, with the EV profiles randomly selected from the Mini-E dataset. The lower and upper bound correspond to the $10 \%$ (green) and $90 \%$ (red) quantile respectively. The red curve in particular in Figures 2 and 3 reveal the potential prominent peaks that result due to heavily incentivised night-time charging. 


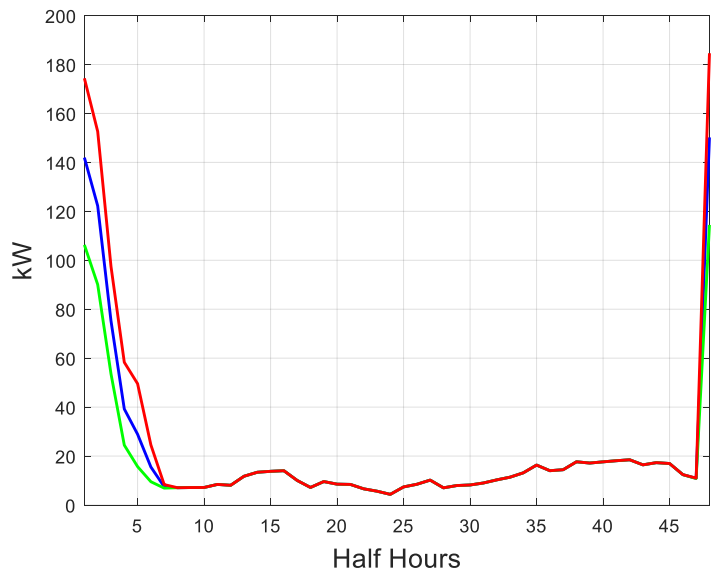

Figure 2: Mini-E 50\% summer penetration at feeder 67 with 35 households. Red: $\mathbf{9 0} \%$ quantile, blue: $\mathbf{5 0 \%}$ quantile, green: $10 \%$ quantile.

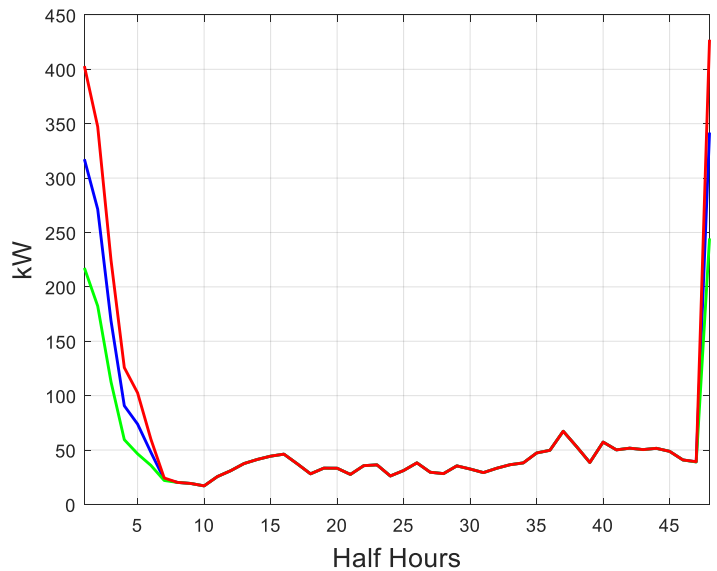

Figure 3: Mini-E 50\% summer penetration at feeder 72 with 99 households. Red: $90 \%$ quantile, blue: $50 \%$ quantile, green: $10 \%$ quantile.

\section{Results using the My Electric Avenue trial dataset}

The results at feeders 67 and 72 for $50 \%$ EV uptake that used the My Electric Avenue dataset on the same networks are given in Figures 4 and 5. The depicted quantiles were also computed from 500 runs, with the same method applied. Since now the EV charging is unrestricted, the significant night-time peaks that were previously exhibited are no longer observed. Instead, the addition to the base-load is somewhat more evenly distributed throughout the day. Although, the unrestricted charging does increase the early evening load, which is the most popular charging period in the My Electric Avenue dataset. This is typically the time of highest national electricity demand and consequently the time of highest electricity prices. On a national level, shifting demand outside this period is desirable. However, overincentivising this shift through stark time of use pricing or direct action could cause the much larger and potentially damaging local LV network peaks shown in Figures 2 and 3.

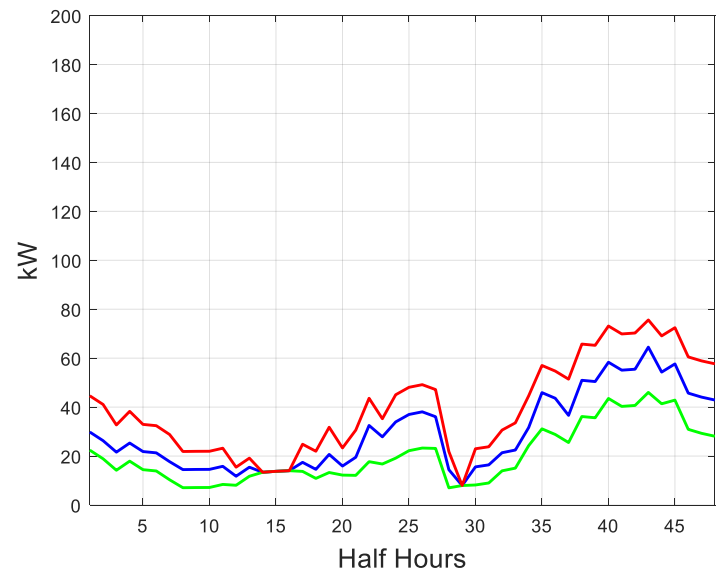

Figure 4: My Electric Avenue 50\% summer penetration at feeder 67 with 35 households. Red: $90 \%$ quantile, blue: $50 \%$ quantile, green: $10 \%$ quantile.

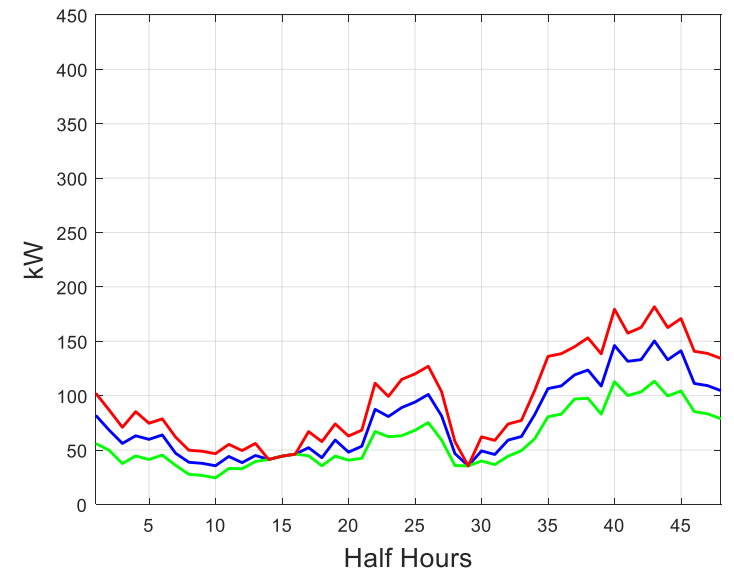

Figure 5: My Electric Avenue 50\% summer penetration at feeder 72 with 99 households. Red: $\mathbf{9 0 \%}$ quantile, blue: $\mathbf{5 0 \%}$ quantile, green: $10 \%$ quantile.

\section{Results for all feeders}

In Figure 6, a summary of the results for all 98 feeders is displayed. The blue and red trends relate to the Mini-E trial and the My Electric Avenue trial respectively. These curves represent a feeder index that is calculated by taking the maximum value of the $90 \%$ feeder quantile (the base-load has been subtracted) and then dividing this by the number of households along the feeder. The 98 feeders have been sorted according to each feeder's proportion of larger homes, where the concentration of larger homes increases with the feeder number. We have used the households' council tax bands to determine this ranking. Overall, the feeder load and the feeder number appear to be correlated. This is the result of influencing the selection of initial EV properties using council tax band information, as previously discussed. More importantly from Figure 6, when comparing the loads at each feeder due to non-incentivised and incentivised charging, we see a substantial increase, further highlighting the negative impact of synchronised EV charging. Note that feeder 1 possesses zero households (only commercial properties, which are not assigned EVs 
in our simulations) and therefore, receives zero load.

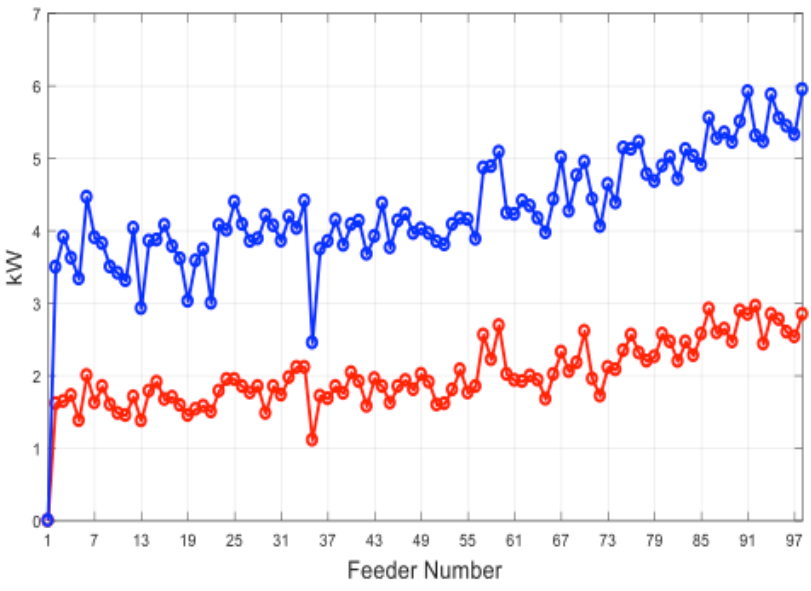

Figure 6: A comparison of the feeder index (50\% EV uptake). Blue: Mini-E trial, red: My Electric Avenue trial. Note that an adjustment is made to the My Electric Avenue dataset to reflect $7.4 \mathrm{~kW}$ chargers being used, which is consistent with the Mini-E trial. This adjustment applies the same start-of-charge times as the $3.7 \mathrm{~kW}$ chargers from the My Electric Avenue trial and the 'ontime' is reduced by approximately half (rounded up to the nearest half hour)

\section{DISCUSSION}

We compared the effects that restricted and unrestricted EV charging patterns will have on low voltage networks. More specifically, our focus was the impact of heavily incentivised EV charging during the normally low load, night-time period. Such incentives may be used in a targeted time-of-use tariff scheme. By simulating this more extreme charging behaviour, our results revealed significant additions to the base-load. The large peaks that were exhibited could potentially cause extensive problems for network operators. In contrast, such sizeable peaks were avoided when EV charging was unrestricted, allowing for a variety of charging activity.

The problems discussed here have some similarities to the network issues associated with Economy 7 customers in the UK. Economy 7 is a restrictive tariff that encourages household electric storage heating to occur during the night and consequently, large night time loads result. The predominance of electric storage heating is known when the network is designed, and therefore this undiversified load is accounted for at this stage. This results in networks with a greater concentration of Economy 7 customers having higher capacity than those without.

Since EV demand is instead being retrofitted to the network, certain mechanisms that reintroduce diversity into the system will be required to prevent extreme cases of simultaneous charging. Techniques that could be employed include the use of storage and cyclical demand control. However, it is important that the impact of all strategies at both national and local levels is considered. From a national perspective, it is necessary to encourage off-peak charging to shift load away from periods of marginal capacity. Whereas at a local level, as demonstrated here, over-incentivised customers cause a loss of natural diversity, which can result in significant peaks and potential network damage, where new, large LV loads cluster. On networks susceptible to EV clustering, moderating mechanisms will be required to be employed to prevent local overloads due to undiversified charging, whilst still allowing customers to benefit from future national demand response initiatives.

\section{Acknowledgment}

This work was carried out with the support of Scottish and Southern Electricity Networks through the New Thames Valley Vision Project (SSET203 New Thames Valley Vision) http://www.thamesvalleyvision.co.uk funded by the Low Carbon Network Fund established by Ofgem.

\section{REFERENCES}

[1] M. Liu, P. McNamara, R. Shorten, S. McLoone, 2015, "Residential electrical vehicle charging strategies: the good, the bad and the ugly." Journal of Modern Power Systems and Clean Energy 3(2), 190-202

[2] J.Y. Yong, V.K. Ramachandaramurthy, K.M. Tan, N. Mithulananthan, 2015, "A review on the state-ofthe-art technologies of electric vehicle, its impacts and prospects." Renewable and Sustainable Energy Reviews, 49, 365 - 385

[3] J. Mullan, D. Harries, T. Braunl, S.Whitely, 2011, "Modelling the impacts of electric vehicle recharging on the Western Australian electricity supply system." Energy Policy 39(7), 4349-4359

[4] A. Navarro-Espinosa, L.F. Ochoa, 2016, "Probabilistic impact assessment of low carbon technologies in LV distribution systems." IEEE Transactions on Power Systems 31(3), 2192- 2203

[5] A. Poghosyan, D. Vukadinovic Greetham, S. Haben, T. Lee, (2015) "Long term individual load forecast under different electrical vehicles uptake scenarios" Applied Energy, 157, 699 - 709

[6] L. Hattam D. Vukadinovic Greetham (2016) "Green neighbourhoods in low voltage networks: measuring impact of electric vehicles and photovoltaics on load profiles" Journal of Modern Power Systems and Clean Energy, doi:10.1007/s40565-016-0253-0

[7] G.Giasemidis, S. Haben, T. Lee, C. Singleton (2016) "A genetic algorithm approach for modelling low voltage network demands" arXiv preprint arXiv: 1612.0683 